PAPER

\title{
Carotid sinus syndrome is common in dementia with Lewy bodies and correlates with deep white matter lesions
}

\author{
R A Kenny, F E Shaw, J T O'Brien, P H Scheltens, R Kalaria, C Ballard
}

J Neurol Neurosurg Psychiatry 2004;75:966-971. doi: 10.1136/jnnp.2003.023812

See end of article for authors' affiliations

Correspondence to: Professor R A Kenny, Institute for Ageing and Health and MRC

Development Centre for Clinical Brain Ageing, Falls and Syncope Service, Victoria Wing, Royal Victoria infirmary Newcastle upon Tyne NE1 $4 \mathrm{LP}, \mathrm{UK}$; anne.harrison@ ncl.ac.uk

Received 23 July 2003 Revised 25 November 2003

Accepted

30 December 2003

\begin{abstract}
Background: Carotid sinus syndrome (CSS) is a common cause of syncope in older persons. There appears to be a high prevalence of carotid sinus hypersensitivity (CSH) in patients with dementia with Lewy bodies (DLB) but not in Alzheimer's disease.

Objective: To compare the prevalence of CSH in DLB and Alzheimer's disease, and to determine whether there is an association between $\mathrm{CSH}$ induced hypotension and brain white matter hyperintensities on magnetic resonance imaging (MRI).

Methods: Prevalence of CSH was compared in 38 patients with DLB (mean (SD) age, 76 (7) years), 52 with Alzheimer's disease (80 (6) years), and 31 case controls (73 (5) years) during right sided supine carotid sinus massage (CSM). CSH was defined as cardioinhibitory $\left(\mathrm{ClCSH}_{;}>3 \mathrm{~s}\right.$ asystole) or vasodepressor (VDCSH; $>30 \mathrm{~mm} \mathrm{Hg}$ fall in systolic blood pressure (SBP)). T2 weighted brain MRI was done in 45 patients (23 DLB, 22 Alzheimer). Hyperintensities were rated by the Scheltens scale.

Results: Overall heart rate response to CSM was slower (RR interval $=3370 \mathrm{~ms}$ (640 to 9400)) and the proportion of patients with CICSH greater (32\%) in DLB than in Alzheimer's disease (1570 (720 to 7800); $11.1 \%)$ or controls (1600 (720 to 3300); 3.2\%) ( $<<0.01)$ ). The strongest predictor of heart rate slowing and CSH was a diagnosis of DLB (Wald 8.0, $\mathrm{p}<0.005$ ). The fall in SBP during carotid sinus massage was greater with DLB $(40(22) \mathrm{mm} \mathrm{Hg})$ than with Alzheimer's disease $(30$ (19) mm Hg) or controls (24 (19) $\mathrm{mm} \mathrm{Hg}$ ) (both $\mathrm{p}<0.02$ ). Deep white matter hyperintensities were present in 29 patients $(64 \%)$. In DLB, there was a correlation between magnitude of fall in SBP during CSM and severity of deep white matter changes $(R=0.58, \mathrm{p}=0.005)$.

Conclusions: Heart rate responses to CSM are prolonged in patients with DLB, causing hypotension. Deep white matter changes from microvascular disease correlated with the fall in SBP. Microvascular pathology is a key substrate of cognitive impairment and could be reversible in DLB where there are exaggerated heart rate responses to carotid sinus stimulation.
\end{abstract}

Dementia is becoming progressively more important as the population ages and the consequent burden of health care and costs increase. ${ }^{11}$ Five per cent of over 65 s and $20 \%$ of over 80 s suffer from dementia. Alzheimer's disease accounts for approximately $60 \%$ of cases, and dementia with Lewy bodies (DLB) for a further $20 \% .{ }^{12}{ }^{13}$ We have observed in our clinical practice that carotid sinus hypersensitivity is common in patients with dementia, particularly those with DLB. This clinical observation was supported by recent pilot data. ${ }^{14}$

A high prevalence of carotid sinus hypersensitivity in DLB is consistent with prominent cholinergic deficits particular to DLB $^{15}$ which could theoretically predispose to some of the parasympathetically mediated heart rate abnormalities of carotid sinus hypersensitivity. ${ }^{16}$ Conversely, recent data have confirmed cardiac sympathetic denervation in DLB patients which was not evident in Alzheimer's disease or controls, and such denervation is consistent with unopposed, and thus exaggerated, parasympathetic activity. ${ }^{18} 19$

The incidence of falls in patients with dementia is fivefold that of the general older population and is particularly high

\footnotetext{
Abbreviations: ADRDA, Alzheimer's Disease and Related Disorders Association; $\mathrm{BGH}$, basal ganglia hyperintensity; $\mathrm{CICSH}$, cardioinhibitory carotid sinus hypersensitivity; CSH, carotid sinus hypersensitivity; CSM, carotid sinus massage; CSS, carotid sinus syndrome; DLB, dementia with Lewy bodies; DWMH, deep white matter hyperintensity; MMSE, minimental state examination; NINCDS, National Institute of Neurological and Communicative Disorders; PVH, periventricular hyperintensity; VDCSH, vasodepressor carotid sinus hypersensitivity
} 
in patients with DLB. ${ }^{20}$ If the prevalence of the bradyarrhythmic component CICSH is high, it may offer an important option for therapeutic intervention for the prevention of falls in dementia-symptoms which have hitherto been notoriously difficult to treat.

Hyperintense lesions detected by magnetic resonance imaging (MRI) often occur in elderly patients, especially those with dementia. ${ }^{21}$ They include periventricular (PVH), basal ganglia $(\mathrm{BGH})$, and deep white matter hyperintensities (DWMH). Correlative neuropathological studies have suggested that DWMH are the result of microvascular pathology. ${ }^{22}$ This is consistent with evidence that hypertension is a key risk factor. Although less studied, episodic hypotension, with associated hypoperfusion, may also be important. ${ }^{23}$ Such episodes are common in patients with carotid sinus hypersensitivity. Microvascular pathology as a key substrate of cognitive impairment has been emphasised in recent reports. ${ }^{24}$ On the basis of previous preliminary observations, ${ }^{25}$ it is therefore likely that carotid sinus hypersensitivitywhich results in repeated hypotensive episodes-will be associated with more severe microvascular pathology.

We hypothesised that carotid sinus hypersensitivity is more prevalent in patients with DLB than in Alzheimer's dementia, and that the magnitude of the fall in systolic blood pressure during carotid sinus massage is associated with the severity of white matter hyperintensities on MRI.

\section{METHODS}

\section{Clinical sample}

The prevalence of carotid sinus hypersensitivity in patients with DLB was compared with the prevalence in Alzheimer patients and non-demented case controls. Consecutive dementia patients seen by old age psychiatrists within the Institute for Ageing and Health in Newcastle upon Tyne, UK, were recruited from the dementia case register. Patients had a detailed clinical assessment, including a standardised history $^{26}$ (history and aetiology schedule), a cognitive assessment (mini-mental state examination, MMSE), ${ }^{27}$ and a physical examination (including the modified unified Parkinson's disease rating scale, UPDRS). ${ }^{28}$ The clinical diagnosis of DLB was made using the consensus criteria ${ }^{29}$ and probable Alzheimer's disease was diagnosed using the NINCDS-ADRDA system. ${ }^{30}$ For the first 50 cases from the series coming to necropsy, the positive predictive values were 95\% for DLB and 80\% for Alzheimer's disease against the necropsy diagnosis. ${ }^{31}$ Only cases of probable DLB and Alzheimer's disease were included. Cases of possible Alzheimer's disease, possible DLB, or vascular dementia were excluded. Patients taking acetylcholinesterase drugs were also excluded.

Case controls who had no history of falls or syncope during the previous three years and who had an MMSE score of $>27$ were recruited from poster advertising in outpatient clinics.

The study was approved by the Newcastle ethics committee, and informed consent was obtained from participants or from informants.

\section{Cardiovascular assessment}

All study participants had neurological and cardiovascular assessments including full clinical examination, resting 12 lead surface ECG, and heart rate and blood pressure responses to right supine carotid sinus stimulation.

Carotid sinus stimulation was carried out after 10 minutes of supine rest, in a quiet laboratory, in the mornings between 0900 and 1100 hours. Phasic blood pressure (measured by the non-invasive, continuous technique of digital photoplethysmography; Finapres, Ohmeda) and continuous heart rate (12 lead surface ECG, $25 \mathrm{~mm}$ paper speed) were recorded during, and for two minutes after, carotid sinus massage. Firm massage was carried out over the right carotid sinus for five seconds. The carotid sinus location was the point of maximum pulsation of the carotid artery, two finger breadths below the angle of the jaw and level with the thyroid cartilage border. ${ }^{132} 33$

Contraindications to carotid sinus massage included recent myocardial infarction (within three months), recent transient ischaemic episode or stroke (within three months), and any history of ventricular fibrillation. ${ }^{34-36}$

Cardioinhibitory or mixed carotid sinus hypersensitivity (CICSH) was defined as three seconds or more of asystole with or without an associated vasodepressor response, and vasodepressor carotid sinus hypersensitivity as a fall of $30 \mathrm{~mm} \mathrm{Hg}$ or more in systolic blood pressure in patients in whom the heart rate response was less than three seconds. ${ }^{1}$

Current prescriptions were recorded for each patient. Drugs were classified according to whether they were known to cause or exaggerate bradycardia or hypotension. ${ }^{37}$

\section{Neuroimaging}

MRI was done using a 1.0 Tesla Siemens scanner. Axial whole brain images of $5 \mathrm{~mm}$ thickness were obtained using proton density weighted and $\mathrm{T}_{2}$ weighted turbo/fast spin echo sequences to allow detailed visualisation of periventricular, deep white matter, and basal ganglia hyperintensities, rated on the Scheltens scale, ${ }^{38}$ which produces a composite measure of severity based upon the number, size, and distribution of lesions, by an expert rater (PS), blind to the results of the cardiovascular assessment. Significant periventricular hyperintensities were defined as $\geqslant 2$; significant deep white matter intensities were defined as $\geqslant 1$; and significant basal ganglia hyperintensities were defined as $\geqslant 1$, as defined in a preliminary publication. ${ }^{25}$

\section{Statistics}

A comparison between subjects with Alzheimer's disease and DLB was the primary aim of the research. Each group was compared separately with control subjects. This applies to all variables analysed. As two primary comparisons were undertaken, a significance of $2.5 \%$ rather than $5 \%$ was adopted.

Continuous variables (age, blood pressure) were plotted to check for outliers and wildly skewed distributions. The distribution of data was normal with the exception of RR interval responses to carotid sinus massage.

Statistics are reported as mean (SD) for all comparisons, with the exception of RR interval response to carotid sinus massage, which was reported as median (extreme range).

Other comparisons were evaluated as secondary analyses. As other factors such as age, sex, blood pressure, and cardiovascular drug treatment have previously been reported as associations of carotid sinus hypersensitivity, an additional analysis was undertaken when significant differences were identified using logistic regression.

For continuous variables such as age and blood pressure, pairwise comparisons between groups were made using an independent sample $t$ test, and for binary variables (such as sex) pairwise comparisons were made using a $\chi^{2}$ test. For the MRI evaluations, the partial correlations (controlling for age) of $\mathrm{PVH}, \mathrm{BGH}$, and DWMH with fall in systolic blood pressure during carotid sinus massage were evaluated with using Pearson's R. Evaluations were undertaken with the SPSS computerised statistics package (version 9). ${ }^{39}$

\section{RESULTS}

Ninety patients with dementia were recruited (52 with Alzheimer's disease and 38 with DLB), along with 31 case controls. No participants had contraindications to carotid sinus massage. Both Alzheimer and DLB patients were older than controls and the Alzheimer patients were older than 
Table 1 Demographic details and resting systolic and diastolic recordings in patients with dementia with Lewy bodies, Alzheimer's disease, and case controls

\begin{tabular}{lllllll}
\hline & & & & \multicolumn{3}{l}{ Significance (p value) } \\
\cline { 6 - 7 } Variable & DLB & AD & Control & DLB v AD & DLB v control & AD v control \\
\hline Number & 38 & 52 & 31 & & & \\
Age (years) & $76(7)$ & $80(6)$ & $73(5)$ & 0.007 & 0.01 & 0.000 \\
Female (\%) & $21(55)$ & $31(60)$ & $12(39)$ & 0.59 & 0.21 & 0.07 \\
MMSE & $16(6)$ & $17(6)$ & & 0.462 & & \\
SBP (mm Hg) & $135(36)$ & $139(25)$ & $147(25)$ & 0.453 & 0.074 & 0.206 \\
DBP (mm Hg) & $72(18)$ & $74(16)$ & $83(15)$ & 0.466 & 0.004 & 0.010 \\
\hline
\end{tabular}

Values are mean (SD) unless stated.

$A D$, Alzheimer's disease; DBP, diastolic blood pressure; DLB, dementia with Lewy bodies; MMSE, mini-mental state examination; SBP, systolic blood pressure.

DLB patients. Sex distribution was similar for patients and controls. Cognitive function (MMSE) was similar for DLB and Alzheimer patients (table 1).

Comorbidity did not differ for dementia subtypes or case controls. No participants had previous stroke, five had treated hypertension (two DLB, one Alzheimer, two controls), two had diabetes mellitus (one DLB, one control), four had symptoms of ischaemic heart disease (two Alzheimer, two controls), one DLB patient had chronic obstructive airways disease, two cases had epilepsy (one DLB, one control), and six had heart failure (two DLB, two Alzheimer, two controls).

The prescription of cardiovascular drugs known to cause or exacerbate bradycardia or hypotension was also similar in all groups:

- DLB: diuretics (4), isosorbide (1), nifedepine (1), prazosin (1);

- Alzheimer's disease: digoxin (1), diltiazem (1), isosorbide (2);

- Controls: ACE inhibitors (1), diuretics (2), isosorbide (2) and nifedepine (1).

No patients were taking antiparkinsonism drugs.

\section{Cardiovascular responses}

All patients were in sinus rhythm. Resting systolic blood pressures were similar for DLB, Alzheimer's disease, and controls (table 1). Resting diastolic blood pressures were significantly lower in dementia patients $(73,(17) \mathrm{mm} \mathrm{Hg}$ ) than in the controls ( 83 (15) $\mathrm{mm} \mathrm{Hg;}<<0.004$ ), but did not differ for dementia subtypes.

In DLB patients the overall heart rate slowing during carotid sinus massage was significantly longer than in either Alzheimer patients $(p<0.001)$ or controls $(p<0.001)$. The number of patients with CICSH was also greater in DLB$31.5 \%$ had CICSH, compared with $11.5 \%$ in the Alzheimer group $(p<0.02)$ and $3.2 \%$ in the controls $(p<0.003)$. Both the degree of heart rate slowing and the frequency of CICSH were similar for Alzheimer patients and controls. The overall fall in SBP during carotid sinus massage (table 2 ) was more marked in DLB than in Alzheimer's disease $(\mathrm{p}<0.017)$ or case controls $(p<0.002)$; this most probably reflects the slower heart rates in DLB in response to carotid sinus massage, because the prevalence of VDCSH did not differ for Alzheimer's disease (38.4\%), DLB (26\%), or case controls $(36.6 \%)$ when patients with CICSH were excluded from the analyses.

When using a stepwise logistic regression analysis to explore the relative influences of risk factors on the diagnosis of CICSH, the only variable selected was the diagnosis of DLB (Wald 6.3, $\mathrm{p}<0.001$ ). Other variables were age (Wald 1.1, $\mathrm{p}=0.29$ ), sex (Wald 0.8, p=0.37), SBP (Wald 3.1, p=0.08),
DBP (Wald 0.1, p=0.78), and cardiovascular drugs (Wald $0.3, \mathrm{p}=0.59)$.

\section{MRI data}

Forty five patients (23 DLB, mean (SD) age, 75 (6.4) years, MMSE 17.2 (4.6), 44\% female; 22 Alzheimer's disease, mean age 78.6 (3.9) years, MMSE 17.9 (4.4), 60\% female) had MRI scans. Mean RR interval was 2200 ms (920 to 8720) in DLB and $1200 \mathrm{~ms}$ (800 to 7800) in Alzheimer's disease; average fall in SBP during carotid sinus massage was $40 \mathrm{~mm} \mathrm{Hg}$ (18 to 53 ) in DLB and $33 \mathrm{~mm} \mathrm{Hg}$ (0 to 88) in Alzheimer's disease. Nineteen $(42.2 \%)$ of the patients had significant basal ganglia hyperintensities (BGH), 29 (64.4\%) had significant deep white matter changes (DWMH), and 43 (96\%) had significant periventricular hyperintensities $(\mathrm{PVH})$. The severity of DWMH was greater in DLB patients than in Alzheimer patients $(6.5(0.94) \vee 3.9(3.1) ; t=2.1, \mathrm{p}=0.04)$ but PVH and BGH did not differ between DLB and Alzheimer's disease: PVH, $3.2(1.3) v 3.3$ (1.0); $t=0.1, \mathrm{p}=0.91 ; \mathrm{BGH}, 0.96(1.49) v$ $0.53(0.94) ; t=1.0, \mathrm{p}=0.30$.

Seventeen patients (38\%) had CICSH and 26 (58\%) had VDCSH. In DLB patients there was a significant association between the magnitude of fall in blood pressure and the severity of DWMH, and a trend towards an association with $\mathrm{BGH}$, but no relation with the severity of PVH. No significant associations were evident between the length of the RR interval after carotid sinus massage and any of the categories of hyperintense lesion. In the Alzheimer patients $(n=22)$ there were no significant associations between hyperintense lesions and either the magnitude of blood pressure fall or the prolongation of RR interval (table 3 ). There was no evidence in the DLB cases that systolic blood pressure, diastolic blood pressure, age, or MMSE were confounding factors.

\section{DISCUSSION}

Patients with DLB were more likely to have CICSH and overall had much more marked slowing of heart rate and a more marked fall in systolic blood pressure in response to carotid sinus massage than either patients with Alzheimer's disease or normal age matched controls. Neither the prevalence of $\mathrm{CICSH}$, the degree of heart rate slowing, nor the fall in SBP during carotid sinus massage differed between Alzheimer patients and controls. Although the control subjects were younger than the dementia patients, the magnitude of the difference in prevalence of CICSH is unlikely to be explained by an average age difference of five years. Indeed, the diagnosis of DLB was independently associated with CICSH and with the extent of heart rate slowing in response to carotid sinus stimulation when other variables which differed between the groups, such as age, were considered. These findings present important and previously unrecognised options for the possible treatment 
Table 2 Haemodynamic responses in heart rate and blood pressure to right supine carotid sinus massage in patients with dementia with Lewy bodies, Alzheimer's disease, and case controls

\begin{tabular}{|c|c|c|c|c|c|c|}
\hline \multirow[b]{2}{*}{ Variable } & \multirow[b]{2}{*}{ DLB } & \multirow[b]{2}{*}{$A D$} & \multirow[b]{2}{*}{ Control } & \multicolumn{3}{|l|}{ Significance } \\
\hline & & & & DLB v AD & DLB $v$ control & $A D v$ control \\
\hline \multirow{2}{*}{\multicolumn{7}{|c|}{$\begin{array}{l}\text { n } \\
\text { RR interval response (ms) }\end{array}$}} \\
\hline & & & & & & \\
\hline $\begin{array}{l}\text { (median) } \\
\text { Range }\end{array}$ & $\begin{array}{l}3370 \\
640 \text { to } 9400\end{array}$ & $\begin{array}{l}1570 \\
720 \text { to } 7800\end{array}$ & $\begin{array}{l}1600 \\
720 \text { to } 3300\end{array}$ & $p<0.001, z=3.4$ & $p<0.001, z=3.2$ & $p=0.49, z=0.69$ \\
\hline $\begin{array}{l}\text { Fall in SBP during CSM } \\
(\mathrm{mm} \mathrm{Hg}) \text { (mean (SD)) }\end{array}$ & $40(22)$ & 30 (19) & $24(19)$ & $\begin{array}{l}p=0.017, t=2.4 \\
d f=88\end{array}$ & $\begin{array}{l}\mathrm{p}<0.002, t=3.2, \\
\mathrm{df}=77\end{array}$ & $p=0.21, t=1.3, d f=81$ \\
\hline Number with CICSH & $12(31.5 \%)$ & $6(11.5 \%)$ & $1(3.2 \%)$ & $\begin{array}{l}p=0.02, \chi^{2}=5.5, \\
d f=1\end{array}$ & $\begin{array}{l}p=0.003, \chi^{2}=7.2 \\
d f=1\end{array}$ & $\begin{array}{l}p=0.19, \chi^{2}=0.8 \\
d f=1\end{array}$ \\
\hline Number with VDCSH & $10 / 26(38 \%)$ & $12 / 46(26 \%)$ & $11 / 30(37 \%)$ & $\begin{array}{l}p=0.27, \chi^{2}=0.69 \\
d f=1\end{array}$ & $\begin{array}{l}p=0.89, \chi^{2}=0.004 \\
d f=1\end{array}$ & $\begin{array}{l}p=0.33, \chi^{2}=0.53 \\
d f=1\end{array}$ \\
\hline $\begin{array}{l}\text { Fall in SBP in subjects } \\
\text { without } \mathrm{ClCSH}(\mathrm{mm} \mathrm{Hg})\end{array}$ & $38(19)$ & $27(18)$ & $24(19)$ & $\begin{array}{l}p=0.02, t=2.3 \\
d f=88\end{array}$ & $\begin{array}{l}p<0.01, t=0.26 \\
d f=77\end{array}$ & $\begin{array}{l}p=0.51, t=0.66 \\
d f=81\end{array}$ \\
\hline \multicolumn{7}{|c|}{$\begin{array}{l}\text { For continuous variables (age and blood pressure), pairwise comparisons between groups were made using an independent sample } t \text { test, and for binary variables } \\
\text { pairwise comparisons were made using a } \chi^{2} \text { test. A Mann-Whitney U test was used for comparison of RR interval response. } \\
\text { AD, Alzheimer's disease; CICSH, cardioinhibitory carotid sinus hypersensitivity ( } \geqslant 3 \text { s asystole in response to carotid sinus massage); CSM, carotid sinus massage; } \\
\text { DBP, diastolic blood pressure; DLB, dementia with Lewy bodies; SBP, systolic blood pressure; VDCSH, vasodepressor carotid sinus hypersensitivity ( } \geqslant 30 \mathrm{~mm} \mathrm{Hg} \\
\text { fall in systolic blood pressure when patients with CICSH were excluded from the analysis). }\end{array}$} \\
\hline
\end{tabular}

of falls in DLB, which require further study in a prospective series.

It is now well recognised that cardiovascular disorders-in particular CICSH-can cause falls in non-demented older adults. $^{37}{ }^{39}$ The reasons for this are twofold. First, up to 30\% of patients with syncope have amnesia for loss of consciousness and only recall falling. ${ }^{40}$ Given that an eye witness account of events is available in less $40 \%$ of cases, ${ }^{6}$ syncope is not reported in these patients. Recall for loss of consciousness is even less likely in patients with dementia. Thus a high proportion of syncopal events which are unwitnessed will be reported as falls. The second explanation is that falls are caused by balance instability resulting from bradycardia induced hypotension in patients with background gait and balance instability. Instability of gait and balance is almost universal in moderate to severe dementia. ${ }^{41}$ Thus a drop in blood pressure, insufficient to cause syncope, can cause falls in susceptible individuals. In non-demented patients with CICSH, irrespective of whether falls are caused by syncope or by balance instability during hypotension, regularisation of heart rate by cardiac pacing significantly reduces further events. ${ }^{37}$ Falls are a well described clinical feature of parkinsonism and dementia with Lewy bodies. The cause of falls in DLB is probably multifactorial, given that gait and balance instability are so common. ${ }^{20}$ We have not correlated the abnormal haemodynamic responses described in this cross sectional series with prospective data on fall rates. Nonetheless, the consequences of the neurological abnormalities in DLB are likely to be exaggerated by such intermittent and profound changes in heart rate and blood pressure. It is our view that a study of cardiac pacing intervention to modify falls in DLB is now timely.

The reason for the high prevalence of carotid sinus hypersensitivity in DLB is at present speculative. It may be related to the presence of Lewy body pathology at the sites where the reflex is relayed in the brain stem. Afferent impulses from the carotid sinus and aortic arch baroreflexes are modulated at the nucleus tractus solitarius, from whence heart rate and blood pressure responses are mediated through the vagal and sympathetic nerves. ${ }^{41}$ Equally, it may be that reflex control from higher centres is abnormal because of DLB related neuropathological or neurochemical changes. ${ }^{16} 17$ Involvement of effector organs is also a possibility. Studies of cardiac innervation using MIBG scans $^{18} 19$ confirm peripheral sympathetic denervation in DLB, which is not evident in Alzheimer's disease or controls. Cardiac sympathetic denervation would facilitate dominance of cardiac vagal responses consistent with CICSH. The extent

Table 3 Correlation (using Pearson's partial correlation coefficient and controlling for age) of deep white matter hyperintensities, basal ganglia hyperintensities, and periventricular hyperintensities with fall in systolic blood pressure in patients with dementia with Lewy bodies and Alzheimer's disease

\begin{tabular}{|c|c|c|c|c|}
\hline & \multicolumn{2}{|l|}{ DLB } & \multicolumn{2}{|l|}{ AD } \\
\hline & $R$ & $\mathrm{p}$ Value & $R$ & p Value \\
\hline DWML and magnitude of SBP fall & 0.58 & 0.0005 & 0.16 & 0.47 \\
\hline BGH and magnitude of SBP fall & 0.41 & 0.06 & 0.20 & 0.37 \\
\hline PVH and magnitude of SBP fall & 0.25 & 0.26 & -0.09 & 0.71 \\
\hline DWMH and RR interval slowing & 0.05 & 0.86 & -0.13 & 0.61 \\
\hline BGH and RR interval slowing & 0.17 & 0.50 & 0.39 & 0.12 \\
\hline PVH and RR interval slowing & 0.04 & 0.88 & 0.03 & 0.91 \\
\hline DWML and baseline DBP & -0.01 & 0.99 & 0.29 & 0.26 \\
\hline BGL and baseline DBP & -0.28 & 0.23 & 0.05 & 0.85 \\
\hline PVH and baseline DBP & 0.11 & 0.65 & -0.23 & 0.38 \\
\hline
\end{tabular}

$A D$, Alzheimer's disease; BGH, basal ganglia hyperintensities; DBP, diastolic blood pressure; DLB, dementia with Lewy bodies; DWMH, deep white matter hyperintensities; PVH, periventricular hyperintensities; SBP, systolic blood pressure. 
of Lewy body pathology in effector organs such as the cardiac conducting system and the peripheral nerves or vasculature is not yet known. ${ }^{42}$

The bradyarrhythmic response to carotid sinus massage is entirely mediated by the vagus nerve and is abolished by moderate doses of atropine. ${ }^{3}$ Acetylcholinesterase treatments can be expected to exaggerate the bradyarrhythmic response. Syncope after the use of acetylcholinesterase inhibitors has been reported..$^{43}$ Our group has recently described a case of carotid sinus syndrome which was unmasked by the use of acetylcholinesterase inhibitors. ${ }^{44}$ In that case, a cardiac pacemaker was implanted to control symptoms of falls and syncope, and the patient was able to resume acetylcholinesterase treatment without further adverse events. Given the high prevalence of CICSH in DLB, it may be that patients with this condition should be screened for carotid sinus hypersensitivity in advance of starting acetylcholinesterase inhibitors. Prospective studies of carotid sinus hypersensitivity in patients receiving acetylcholinesterase inhibitors are now important, given the proven benefit of these agents in patients with DLB. ${ }^{45}$

Vasodepressor responses, independent of heart rate slowing (VDCSH), are attributed to acute withdrawal of peripheral sympathetic activity to capacitance vessels and arterial vasculature in response to carotid sinus stimulation. ${ }^{46}$ The number of patients with VDCSH was similar for all groups but the overall fall in systolic blood pressure in response to carotid sinus massage was most exaggerated in DLB. These systolic blood pressure differences are a result of the more exaggerated heart rate slowing in DLB patients, and are thus amenable to control by cardiac pacing. ${ }^{9} 3747$

The reason why there was no association between deep white matter changes and the degree of heart rate slowing is not clear, unless the numbers were insufficient to show a difference. However, there was a significant association with the degree of hypotension during carotid sinus massage and DWMH in DLB patients. The greater severity of DWMH in the DLB group is consistent with our hypothesis that carotid sinus hypersensitivity may contribute to these MRI changes because this phenomenon is more frequent in DLB.

Although carotid sinus massage is a crude method for diagnosing carotid sinus hypersensitivity, it is the best one available for identifying the patients who are most likely to benefit from cardiac pacing. ${ }^{97} 47$ In its favour, it is a simple technique that can be applied without the need for sophisticated equipment or expertise, and it is thus a valuable screening tool for application to a prevalent disorder. In nondemented older adults, neurological complication rates from the procedure are $0.4 \% .^{34-36}$ There are no data on the incidence of neurological complications during carotid sinus massage in patients with dementia. To date, most reported neurological complications have occurred during carotid sinus massage carried out with the patient upright. ${ }^{34-36}$ We therefore elected to study the prevalence of carotid sinus hypersensitivity with the patient supine. There were no complications, so we recommend this procedure for screening for carotid sinus hypersensitivity in patients with dementia until more information is available about complication rates in this population.

The association between DWMH and a fall in systolic blood pressure during carotid sinus massage in DLB patients supports our hypothesis that a sudden drop in blood pressure resulting from carotid sinus stimulation is an important potential substrate of white matter pathology, consistent with recent reports indicating that orthostatic hypotension is a risk factor for DWMH. ${ }^{23}{ }^{48}$ The absence of an association in Alzheimer's disease is probably a reflection of the less dramatic falls in blood pressure in that condition compared with DLB. The Schelten's scale is a well validated visual rating instrument for white matter hyperintensities that is more sensitive to change than other scales. ${ }^{38}$

There is accumulating evidence that white matter and basal ganglia hyperintensities are associated with cognitive impairment, especially tests of fronto-executive function, both in demented and non-demented subjects. ${ }^{49-52}$ It is possible that white matter hyperintensities contribute to cognitive dysfunction in patients with DLB. It should also be considered that brain stem pathology may be the substrate of CICSH in DLB-for example, in multisystem atrophy there is a reported association between autonomic failure and catecholaminergic neurones in the ventrolateral medulla. ${ }^{16}$ Furthermore, it is well recognised that Lewy body pathology is prominent in the key brain stem areas ${ }^{29}$ where cardiovascular control is also modulated. These possible associations require further study.

\section{Conclusions}

The extent of both carotid sinus induced heart rate slowing and hypotension is significantly exaggerated in DLB. The degree of hypotension correlates with deep white matter changes and possibly with basal ganglia hyperintensities. These findings may have important implications for successful treatment of falls in some DLB patients, and for screening before starting acetylcholinesterase treatment. They need to be tested in prospective intervention trials.

\section{ACKNOWLEDGEMENTS}

We would like to thank Dr I Nick Steen PhD, senior statistician, for statistical advice.

\section{Authors' affiliations}

R A M Kenny, F E Shaw, J T O'Brien, R Kalaria, C Ballard, MRC Institute for Ageing and Health, University of Newcastle upon Tyne, UK

P H Scheltens, Department of Cognitive Neurology, VU Medical Centre, Amsterdam, Netherlands

Competing interests: none declared

\section{REFERENCES}

1 Brignole M, Alboni P, Benditt D, et al. Guidelines on management (diagnosis and treatment) of syncope. Eur Heart J 2001;22:1256-306.

2 Walter PF, Crawley IS, Dorney ER. Carotid sinus hypersensitivity and syncope. Am J Cardiol 1978;42:396-403.

3 Kenny RA, Mclntosh SJ, Wynne H. Pattern of inhibition of parasympathetic activity in response to incremental bolus doses of atropine in carotid sinus hypersensitivity. Clin Auton Res 1994;4:63-6.

4 Tea SH, Mansourati J, L'Heveder G, et al. New insights into the pathophysiology of carotid sinus syndrome. Circulation 1996:93:1411-16.

5 Allcock LM, O'Shea D. Diagnostic yield and development of a neurocardiovascular investigation unit for older adults in a district hospital. J Gerontol A Biol Sci Med Sci 2000;55:M458-62.

6 McIntosh S, Da Costa D, Kenny RA. Outcome of an integrated approach to the investigation of dizziness, falls and syncope in elderly patients referred to a 'syncope' clinic. Age Ageing 1993;22:53-8.

7 Hudson WM, Morley CA, Perrins EJ, et al. Is a hypersensitive carotid sinus reflex relevant? Clin Prog Electrophysiol Pacing 1985;3:155-9.

8 Brignole M, Menozzi C, Lolli G, et al. Long-term outcome of paced and unpaced patients with severe carotid sinus syndrome. Am J Cardiol 1992;69:1039-43.

9 Morley CA, Perrins E, Grant P, et al. Carotid sinus syndrome treated by pacing. Analysis of persistent symptoms and role of atrioventricular sequential pacing. Br Heart J 1982;47:411-18.

10 da Costa D, Mclntosh S, Kenny RA. Benefits of fludrocortisone in the treatment of symptomatic vasodepressor carotid sinus syndrome. Br Heart J 1993;69:308-10.

11 Audit Commission. Forget me Not: mental health services for older people. London: The Audit Commission, 2000.

12 Rocca WA, Hofman A, Brayne C, et al. Frequency and distribution of Alzheimer's disease in Europe: a collaborative study of 1980-1990 prevalence findings. The EURODEM-Prevalence Research Group. Ann Neurol $1991 ; 30: 381-90$.

13 Perry RH. Senile dementia of Lewy body type. A clinically and neuropathologically distinct form of Lewy body dementia in the elderly. J Neurol Sci 1990;95:119-39.

14 Ballard C, Shaw F, McKeith I, et al. High prevalence of neurovascular instability in neurodegenerative dementias. Neurology 1998;51:1760-2. 
15 Ballard C, Piggott $M$, Johnson $M$, et al. Delusions associated with elevated muscarinic binding in dementia with Lewy bodies. Ann Neurol 2000;48:868-76.

16 Benarroch EE, Schmeichel AM, Parisi JE. Involvement of the ventrolateral medulla in parkinsonism with autonomic failure. Neurology 2000;54:963-8.

17 Wang N, Orr-Urtreger A, Chapman J, et al. Deficiency of $\beta 4$ nicotinic acetylcholine receptor subunits cause autonomic cardiac and intestinal dysfunctions [abstract]. Neurology 2002;59(suppl 3):A88.

18 Yoshita M, Taki J, Yamada M. A clinical role for [(123)I]MIBG myocardial scintigraphy in the distinction between dementia of the Alzheimer's-type and dementia with Lewy bodies. J Neurol Neurosurg Psychiatry 2001;71:583-8.

19 Watanabe H, leda T, Katayama T, et al. Cardiac (123)l-metaiodobenzylguanidine (MIBG) uptake in dementia with Lewy bodies: comparison with Alzheimer's disease. I Neurol Neurosurg Psychiatry 2001:70:781-3.

20 Ballard CG, Shaw F, Lowery K, et al. The prevalence, assessment and associations of falls in dementia with Lewy bodies and Alzheimer's disease. Dement Geriatr Cogn Disord 1999; 10:97-103.

21 Barber R, Scheltens $P$, Gholkar A, et al. White matter lesions on magnetic resonance imaging in dementia with Lewy bodies, Alzheimer's disease, vascular dementia, and normal aging. I Neurol Neurosurg Psychiatry 1999;67:66-72.

22 Skoog I. A review on blood pressure and ischaemic white matter lesions. Dement Geriatr Cogn Disord 1998:9(suppl 1):13-19.

23 Matsushita K, Kuriyama Y, Nagatsuka K, et al. Periventricular white matter lucency and cerebral blood flow autoregulation in hypertensive patients. Hypertension 1994;23:565-8.

24 Esiri MM, Wilcock GK, Morris JH. Neuropathological assessment of the lesions of significance in vascular dementia. J Neurol Neurosurg Psychiatry 1997; 63:749-53.

25 Ballard C, O'Brien J, Barber B, et al. Neurocardiovascular instability, hypotensive episodes, and MRI lesions in neurodegenerative dementia. Ann NY Acad Sci 2000;903:442-5.

26 Dewey ME, Copeland JRM, Lobo A, et al. Computerized diagnosis from a standardised history schedule: a preliminary communication about the organic section of the HAS-AGECAT system. Int I Geriatr Psychiatry 1992; 7:443-6

27 Folstein MF, Folstein SE, McHugh PR. "Mini-mental state". A practical method for grading the cognitive state of patients for the clinician. J Psychiatr Res 1975;12:189-98.

28 Ballard C, McKeith I, Burn D, et al. The UPDRS scale as a means of identifying extrapyramidal signs in patients suffering from dementia with Lewy bodies. Acta Neurol Scand 1997:96:366-71.

29 McKeith IG, Galasko D, Kosaka K, et al. Consensus guidelines for the clinical and pathologic diagnosis of dementia with Lewy bodies (DLB): report of the consortium on DLB international workshop. Neurology 1996;47:1113-24.

30 McKhann G. Drachman D, Folstein M, et al. Clinical diagnosis of Alzheimer's disease: report of the NINCDS-ADRDA Work Group under the auspices of Department of Health and Human Services Task Force on Alzheimer's Disease. Neurology 1984;34:939-44.

31 McKeith IG, Ballard CG, Perry RH, et al. Prospective validation of consensus criteria for the diagnosis of dementia with Lewy bodies. Neurology 2000;54:1050-8

32 O'Shea D, Parry SW, Kenny RA. The Newcastle protocol for carotid sinus massage. J Am Geriatr Soc 2001;49:236-7.
33 Kenny RA, O'Shea D, Parry SW. The Newcastle protocols for head-up tilt table testing in the diagnosis of vasovagal syncope, carotid sinus hypersensitivity, and related disorders. Heart 2000;83:564-9.

34 Munro NC, Mclntosh S, Lawson J, et al. Incidence of complications after carotid sinus massage in older patients with syncope. J Am Geriatr Soc 1994:42:1248-51

35 Davies AJ, Kenny RA. Frequency of neurologic complications following carotid sinus massage. Am J Cardiol 1998;81:1256-7.

36 Richardson DA, Bexton R, Shaw FE, et al. Complications of carotid sinus massage - a prospective series of older patients. Age Ageing 2000;29:413-17.

37 Kenny RA, Richardson DA, Steen N, et al. Carotid sinus syndrome: Modifiable risk factors for non-accidental falls in older adults. J Am Coll Cardiol 2001:38:1491-6.

38 Scheltens $\mathbf{P}$, Barkhof $F$, Leys $D$, et al. A semiquantitative rating scale for the assessment of signal hyperintensities on magnetic resonance imaging. J Neurol Sci 1993;114:7-12.

39 SPSS. Statistical package for the social sciences, Windows version, release 5.0. Chicago: SPSS inc, 1992

40 Kenny RA, Traynor G. Carotid sinus syndrome - clinical characteristics in elderly patients. Age Ageing 1991;20:449-54.

41 Tinetti ME, Baker DI, McAvay G, et al. A multifactorial intervention to reduce the risk of falling among elderly people living in the community. N Engl J Med 1994:331:821-7.

42 Goldstein DS, Holmes CS, Dendi R, et al. Orthostatic hypotension from sympathetic denervation in Parkinson's disease. Neurology 2002;58: 1247-55

43 National Institute for Clinical Excellence. Guidance on the use of donepezil, rivastigmine and galantamine for the treatment of Alzheimer's disease. Technology Appraisal Guidance No 19. London: Department of Health, 2001

44 Newby J, McKeith I, Kenny RA. Acetylcholinesterase inhibitors and cardiac syncope. Dement Geriatr Cogn Disord (in press).

45 McKeith I, Del Ser T, Spano P, et al. Efficacy of rivastigmine in dementia with Lewy bodies: a randomised, double-blind, placebo-controlled international study. Lancet 2000;356:2031-6.

46 Madigan NP, Flaker GC, Curtis JJ, et al. Carotid sinus hypersensitivity: beneficial effects of dual-chamber pacing. Am J Cardiol 1984;53:1034-40.

47 Brignole M, Sartore B, Barra M, et al. Is DDD superior to WVI pacing in mixed carotid sinus syndrome? An acute and medium-term study. PACE 1988; 11:1902-10.

48 Kenny RA, Wesnes K, Stout NR. Cognitive impairment is common in patients with symptomatic orthostatic hypotension. Europace (in press).

49 DeCarli C, Murphy DG, Tranh M, et al. The effect of white matter hyperintensity volume on brain structure, cognitive performance, and cerebral metabolism of glucose in 51 healthy adults. Neurology 1995;45:2077-84.

50 Leaper SA, Murray AD, Lemmon HA, et al. Neuropsychologic correlates of brain white matter lesions depicted on MR images: 1921 Aberdeen Birth Cohort. Radiology 2001;221:51-5.

51 Pantoni L, Leys D, Fazekas F, et al. Role of white matter lesions in cognitive impairment of vascular origin. Alzheimer Dis Assoc Disord 1999;13(suppl 3):S49-54.

52 Salloway S, Malloy P, Kohn R, et al. MRI and neuropsychological differences in early- and late-life-onset geriatric depression. Neurology 1996;46:1567-74 